\title{
The Effect of the Testis on the Ovary: \\ Structure-Function Relationships in a Neonate with a Unilateral Ovotestis (Ovotesticular Disorder of Sex Development)
}

\author{
Siri Atma W. Greeley ${ }^{a}$ Elizabeth Littlejohn ${ }^{a}$ Aliya N. Husain ${ }^{b}$ \\ Darrel Waggoner ${ }^{c}$ Mohan Gundeti ${ }^{d}$ Robert L. Rosenfield ${ }^{a}$ \\ a Departments of Pediatrics and Medicine (Endocrinology), University of Chicago Pritzker School of Medicine, \\ Chicago, IL, USA; ' Department of Pathology, University of Chicago Pritzker School of Medicine, Chicago, IL, USA; \\ 'Department of Human Genetics, University of Chicago Pritzker School of Medicine, Chicago, IL, USA; \\ ${ }^{\mathrm{d}}$ Department of Surgery (Pediatric Urology), University of Chicago Pritzker School of Medicine, Chicago, IL, USA
}

\section{Established Facts}

- Full-term newborns undergo activation of the hypothalamic-pituitary-gonadal axis commencing at about 1 week of age ("neonatal minipuberty").

- There are no data on the neonatal ovarian function of infants with ovotesticular disorder of sex development (DSD).

\section{Novel Insights}

- Ovarian function was neither discernable spontaneously nor in response to gonadotropin stimulation in the presence of functioning testicular tissue in a neonate with ambiguous genitalia due to ovotesticular DSD.

- Hyperfunction of the contralateral ovary rapidly followed ovotestis removal at 3 weeks of age.

\section{Keywords}

Ovotesticular disorder of sexual development - True hermaphroditism · Polycystic ovary syndrome - Ovarian development $\cdot$ Neonatal minipuberty

\section{Abstract}

Aims: To evaluate gonadal function in a newborn with suspected ovotesticular disorder of sex development (DSD). Methods: Gonadal function was evaluated at baseline and after gonadotropin-releasing hormone agonist (GnRHag) stimulation testing. Results: A full-term 46,XX neonate with genital ambiguity produced serum testosterone and antiMüllerian hormone (AMH) levels appropriate for males within days, while serum estradiol remained prepubertal, both spontaneously and in response to GnRHag stimulation testing. Ovotesticular DSD was diagnosed at laparoscopy: the left gonad was an ovotestis and the right gonad an ovary arrested at the primordial follicle stage of development. Mosaicism for an isochromosome of the $Y$ short arm in $6-18 \%$ of

\section{KARGER}

(C) 2017 S. Karger AG, Basel

E-Mail karger@karger.com

www.karger.com/hrp
Siri Atma W. Greeley, MD, PhD

Section of Adult and Pediatric Endocrinology, Diabetes, and Metabolism University of Chicago Medical Center

5841 S. Maryland Ave, MC 1027, Chicago, IL 60637 (USA)

E-Mail sgreeley@uchicago.edu 
gonadal cells was demonstrated. After ovotestis removal at 3 weeks of age, serum AMH became low within a month, but the elevated testosterone was slow to resolve, apparently from ovarian androgenic hyperfunction coincident with ovarian estrogenic hyperfunction and an adult degree of ovarian development. Ovarian morphology and function gradually normalized as neonatal minipuberty waned. Conclusions: In a neonate with genital ambiguity due to ovotesticular DSD, testicular AMH and testosterone production respectively appear to account for the initial arrest of ovarian development and subsequent rapid hyperfunction of the contralateral ovary after ovotestis removal.

(c) 2017 S. Karger AG, Basel

\section{Introduction}

Ovotesticular disorder of sex differentiation (DSD), also termed true hermaphroditism, is defined by the presence of both functional ovarian and testicular tissue $[1,2]$. Ovotesticular DSD accounts for about one percent of the genital ambiguity that results from partial masculinization by fetal testicular tissue [1]. Estradiol secretion by ovotesticular DSD children as young as 5 months occurs in response to the administration of exogenous gonadotropins [3], and ovulation and pregnancy have been reported in several ovotesticular DSD cases [4-6]. Since the pubertal neuroendocrine-gonadal axis is transiently activated in neonates ("neonatal minipuberty") [7], one might expect that in ovotesticular DSD both ovarian and testicular function would be detectable neonatally, though we are aware of no previous studies of this possibility.

In a case with genital ambiguity due to ovotesticular DSD studied within 2 weeks of age, we discovered that ovarian function was not discernable in the presence of testicular function, although ovarian hyperfunction rapidly occurred after removal of the testicular tissue. Our investigations suggest a role in the neonatal period for testicular anti-Müllerian hormone (AMH) secretion in suppressing ovarian follicular development and function, and testicular testosterone secretion in setting the stage for ovarian hyperfunction after removal of the ovotestis.

\section{Case Report}

The patient was born full-term to a primiparous 21-year-old mother who experienced a slight increase in abdominal hirsutism during the pregnancy. Ambiguous genitalia were discovered at birth: the phallus was $3.5 \mathrm{~cm}$ in length with perineal hypospadias and fused, virilized labioscrotal folds; gonads were not palpable. Ultrasound revealed a well-developed uterus and vagina, and left inguinal and right pelvic gonads without discernable ovarian follicles. Peripheral blood karyotype was 46,XX, and fluorescent in situ hybridization for SRY was negative. At day of life (DOL) 6, plasma testosterone was $77 \mathrm{ng} / \mathrm{dL}$, DHEAS $105 \mu \mathrm{g} / \mathrm{dL}$, and estradiol 7 pg/mL (Fig. 1). Congenital adrenal hyperplasia was ruled out by an unremarkable pattern of cortisol precursors, while unremarkable androstenedione levels made aromatase deficiency unlikely. Plasma testosterone remained high (113 ng/dL) after dexamethasone suppression of adrenal function that lowered DHEAS to $<15$ and cortisol to $<0.3 \mu \mathrm{g} / \mathrm{dL}$. Gonadotropin-releasing hormone agonist (GnRHag) testing on DOL 12 revealed adult male
Fig. 1. Baseline pubertal hormone levels before and after removal of ovotestis (orchiectomy). In the first 2 weeks of life, $\mathrm{LH}$ and FSH attained pubertal-adult levels and testosterone $(\mathrm{T})$ rose to a level typical for a mature male, while estradiol (E2) remained at a prepubertal level and the right ovary was small (Fig. 2e). One month after ovotestis removal (DOL 58), serum estradiol had risen to an elevated preovulatory range $(390 \mathrm{pg} / \mathrm{mL})$ and gonadotropins fell, with FSH becoming frankly low (0.6 IU/L). While testosterone fell remarkably (to 62 $\mathrm{ng} / \mathrm{dL}$ ), it was above the normal female range. By DOL 80 , the ovary had enlarged considerably, to an adult size and morphology (Fig. 2f). However, estradiol was falling and FSH rising. The hormone changes and ovarian development (Fig. 2g) were all waning by DOL 114. Conversion to SI units: testosterone $\times 0.0347=\mathrm{nM}$, estradiol $\times 3.61=$ pM.

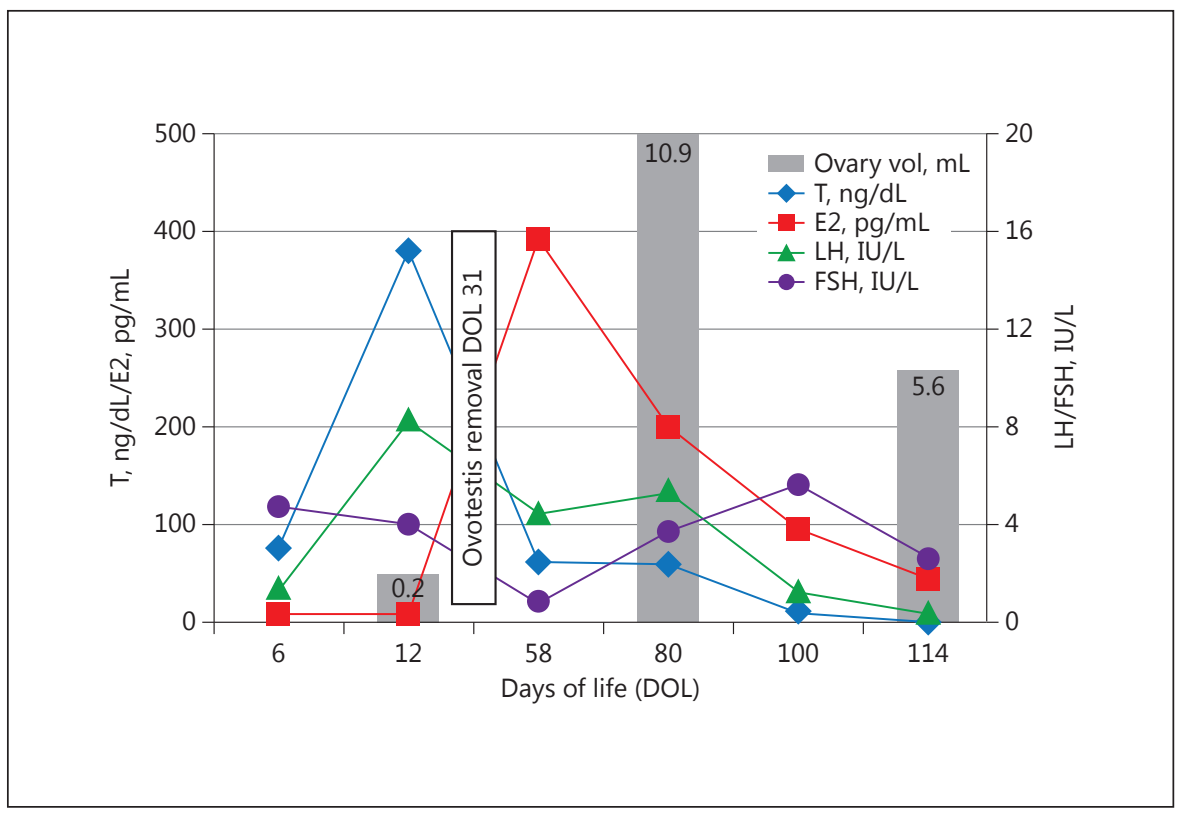


range serum luteinizing and follicle-stimulating hormone $(\mathrm{LH}$, FSH), and testosterone before and after stimulation, yet prepubertal estradiol baseline and response levels (Table 1) [8,9]. Serum AMH was $28 \mathrm{ng} / \mathrm{mL}$, which is very elevated for a female and approximates the lower end of the normal male range for age [10]. Evidence of testicular function in a 46,XX DSD newborn suggested ovotesticular DSD, although there was no evidence of functioning ovarian tissue.

\section{Methods}

This is a single case report, so it does not require IRB approval. All studies were done in the context of clinical care to which the mother consented. Serum LH and FSH were measured by immunofluorometric assays (Delphia ${ }^{\circledR}$, Wallach, Finland). Serum testosterone was measured by direct radioimmunoassay (Diagnostic Products Corporation, DPC, Coat-A-Count ${ }^{\circledR}$, Los Angeles, CA, USA), estradiol by a post-extraction radioimmunoassay (Pantex ${ }^{\circledR}$, Santa Monica, CA, USA), and 17-hydroxyprogesterone (17OHP) by post-chromatographic radioimmunoassay in the University of Chicago Hospital Laboratories (UCHL) [11]; these steroid radioimmunoassays have been validated against liquid chromatography-mass spectrometry methods $[12,13]$. Other hormone levels were measured by commercially available assays at UCHL, Mayo Medical Laboratories (Rochester, MN, USA), or Esoterix (Calabasas Hills, CA, USA). Chromosomal analysis was done by analyzing 50 metaphase cells from each different tissue sample, using florescence in situ hybridization (FISH) to distinguish sex chromosomes using probes specific for $S R Y$ on the short arm of the Y chromosome and a probe for the chromosome X centromere (Abbott Molecular, Des Plaines, IL, USA). Leuprolide acetate (GnRHag) $10 \mu \mathrm{g} /$ $\mathrm{kg}$ was administered subcutaneously after obtaining a baseline blood sample: sampling was performed to respectively test gonadotropin $(4 \mathrm{~h})$ and gonadal steroid $(21 \mathrm{~h})$ peak responses [8, 9].
Dexamethasone $1.0 \mathrm{mg} / \mathrm{m}^{2}$ daily was co-administered during two of the GnRHag tests to blunt coincidental adrenal contributions to $17 \mathrm{OHP}$ and sex steroid levels [11].

\section{Results}

\section{Gonadal Structure and Function}

Laparoscopy on DOL 31 revealed a left inguinal ovotestis with an attached epididymis and distal fallopian tube and a right-sided intrapelvic normal-appearing ovary and fallopian tube attached to a normal uterus. After intraoperative frozen sections revealed testicular tissue with no clean demarcation between testicular and ovarian components, the ovotestis and attached structures were removed to optimize potential fertility as a female. Excisional biopsy of the left gonad revealed both testicular and ovarian (with only primordial follicles) components without clean demarcation, while incisional biopsy of the right ovary showed normal primordial follicles throughout the stroma, with a suggestion of partial transition to primary follicles, without further follicle development (Fig. 2a-d). Chromosomal analysis of operative tissues revealed a mosaic chromosome pattern in both gonads: ovotestis: 41/50 (82\%) 46,XX; 9/50 (18\%) 47XX,+mar.ishi(Y)(p10)(SRY++); ovary: 47/50 (94\%) 46,XX; 3/50 (6\%) 47XX,+mar.ishi(Y)(p10)(SRY++); skin: $50 / 50$ (100\%) 46,XX (-SRY). The Y chromosome had the appearance of an isochromosome with 2 copies of the short arm attached together.

Table 1. GnRHag test baseline and peak responses pre- and post-orchiectomy

\begin{tabular}{|c|c|c|c|c|c|c|c|c|c|c|}
\hline & \multicolumn{2}{|c|}{$\begin{array}{l}\text { Preoperative } \\
(\text { DOL 12-13) }\end{array}$} & \multirow{2}{*}{ 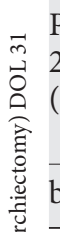 } & \multicolumn{2}{|c|}{$\begin{array}{l}\text { Post-orchiectomy } \\
\text { 27-28 days } \\
\text { (DOL 58-59) }\end{array}$} & \multicolumn{2}{|c|}{$\begin{array}{l}\text { Post-orchiectomy } \\
83-84 \text { days } \\
(\text { DOL } 114-115)^{\mathrm{a}}\end{array}$} & \multirow{2}{*}{$\begin{array}{l}\text { Normal } \\
\text { 1-6-month infant } \\
\text { maxima } \\
\left(\text { female/male) }{ }^{\mathrm{b}}\right. \\
\text { baseline }\end{array}$} & \multicolumn{2}{|c|}{$\begin{array}{l}\text { Normal mature } \\
\text { female }^{c}\end{array}$} \\
\hline & baseline & peak & & baseline & peak & baseline & peak & & baseline & peak \\
\hline Testosterone, ng/dL & 381 & 446 & $\sqrt{\pi}$ & 62 & 82 & $<10$ & 12 & $<5-45 / 50-375$ & $15-50$ & $9-33$ \\
\hline Estradiol, pg/mL & 8 & 13 & 高 & 390 & 729 & 44 & QNS & $<7-55 /<7-35$ & $19-95$ & $73-279$ \\
\hline LH, IU/L & 8.2 & 52 & $\underset{\mathscr{D}}{\mathscr{D}}$ & 4.3 & 80 & 0.2 & 25 & $<0.1-1.1 / 3.0-5.0$ & $1.4-5.6$ & $28-134$ \\
\hline FSH, IU/L & 3.8 & 11 & 苞 & 0.6 & 4.5 & 2.4 & 18 & $1.2-19 / 0.5-2.4$ & $3.0-7.9$ & $12-48$ \\
\hline $\mathrm{AMH}, \mathrm{ng} / \mathrm{mL}$ & - & 28 & o. & 0.2 & 0.1 & - & - & $0.6-4.1 / 105-270$ & $0.4-6.3$ & na \\
\hline $17 \mathrm{OHP}, \mathrm{ng} / \mathrm{dL}$ & - & - & & - & - & $<25$ & 330 & $20-225 / 20-225$ & $\leq 25-34$ & $38-152$ \\
\hline
\end{tabular}

Conversion to SI units: testosterone $\times 0.0347=\mathrm{nM}$, estradiol $\times 3.61=\mathrm{pM}, \mathrm{AMH} \times 7.14=\mathrm{pM}, 17 \mathrm{OHP} \times 0.0303=\mathrm{nM} .{ }^{\mathrm{a}}$ Dexamethasone-suppressed. ${ }^{\mathrm{b}}$ Data from Winter et al. [23] (testosterone and 17OHP at 1-2 month), Bidlingmaier and Knorr [24] (estradiol at 1 week to 6 months), Chellakooty et al. [25] (female LH, FSH at 2-4 months), Bergada et al. [10] (male LH and FSH at 1 month), and Lindhardt Johansen et al. [14] (AMH at 3 months). ${ }^{c}$ Post-menarcheal, mid-follicular phase of cycle; peaks post-dexamethasone [11, 28, 29]. QNS, quantity not sufficient; na, not available. 

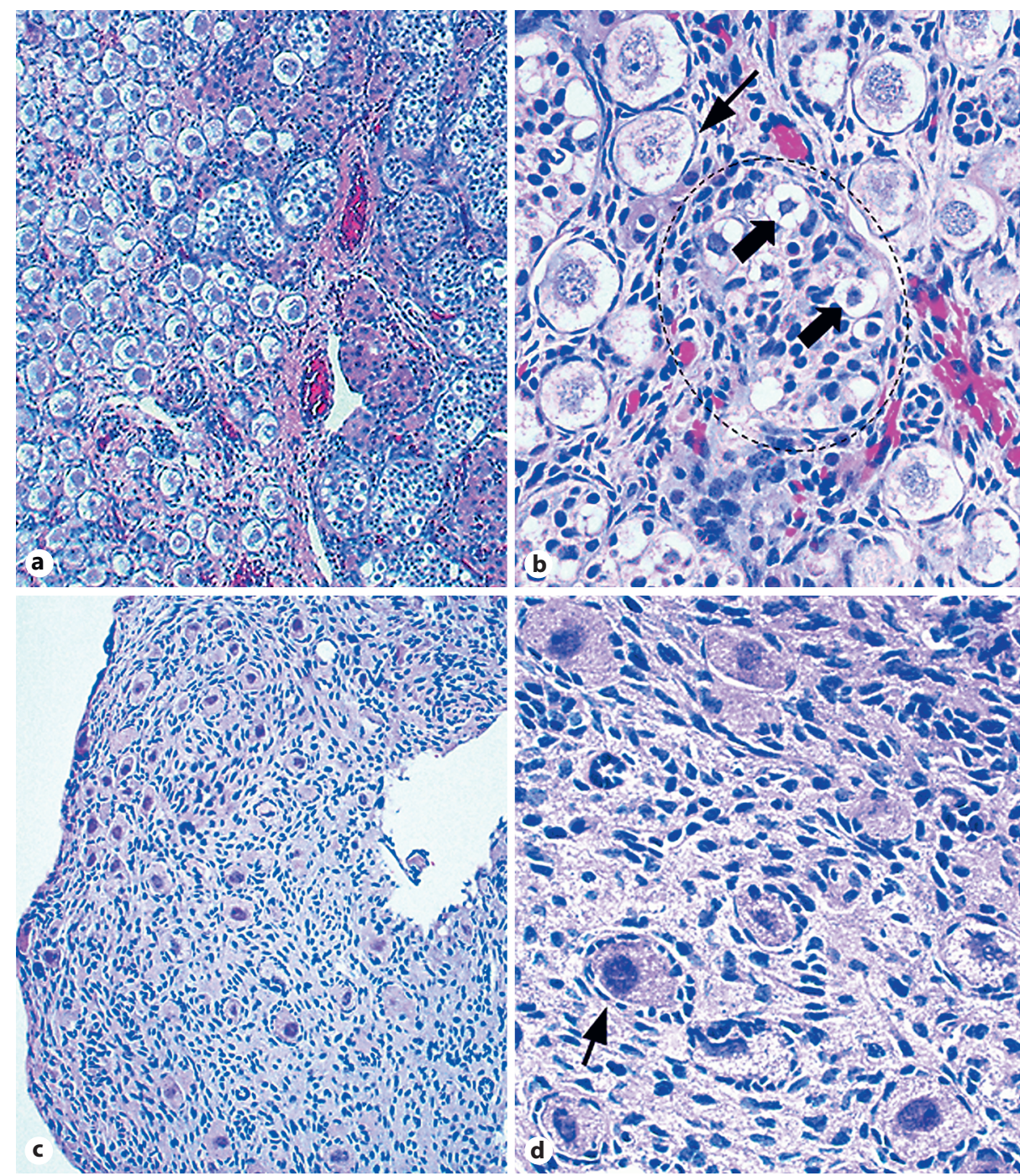
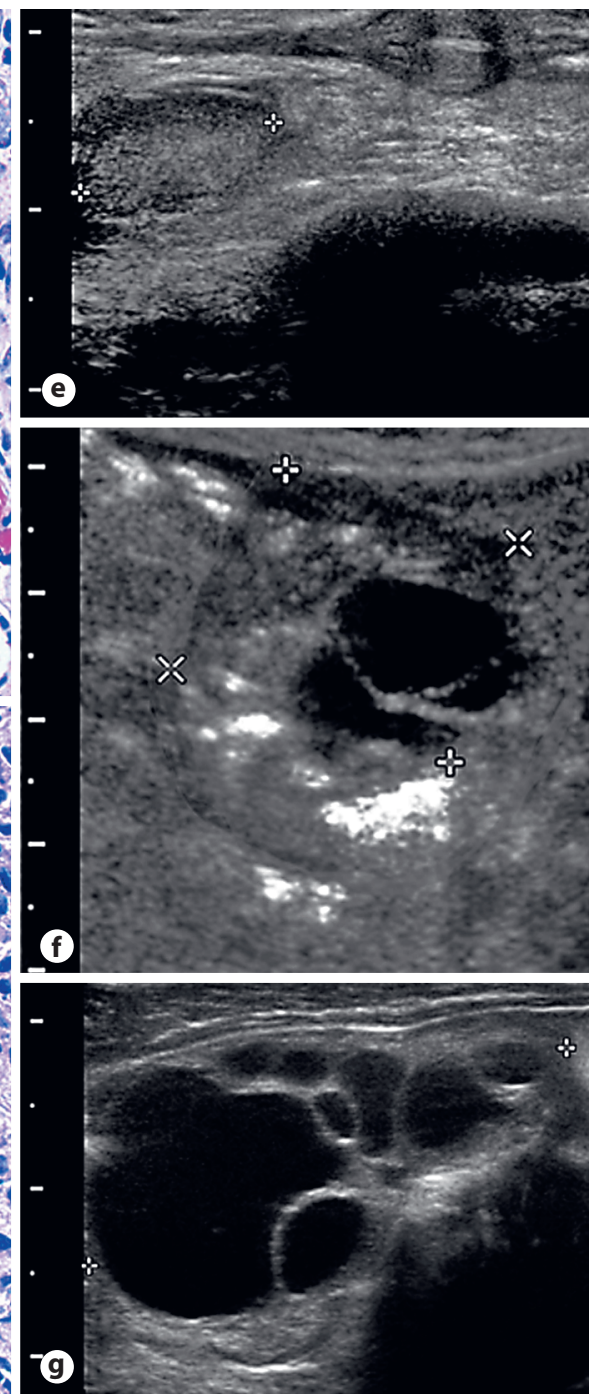

Fig. 2. a-d Gonadal histology. e-g Ultrasound images of the right ovary before and after ovotestis removal. Major scale markers, 1.0 $\mathrm{cm}$. a Ovotestis (left gonad) low-power detail showing subcortical ovarian tissue consisting entirely of primordial follicles and devoid of antral follicles (left), incompletely demarcated from medullary testicular tissue (right). b Ovotestis (left gonad) high-power detail showing seminiferous tubule (within dotted oval) with germ cells (block arrows) in a field of ovarian primordial follicles, which are characteristically encircled by a few flattened pre-granulosa cells (narrow arrow). c Ovary (right gonad) low-power detail of subcapsular region of right ovary, from subcortical area on the left to medullary region on the right. Note that there is no follicle devel-

\section{Ovarian Function after Removal of Ovotestis}

After orchiectomy (i.e., ovotestis removal) on DOL 31, repeat testing was performed at several subsequent time points, in some cases with sampling after stimulation with GnRHag (Fig. 1; Table 1). By DOL 58, 4 weeks after opment beyond the primordial follicle stage and stroma is dense. d Ovary (right gonad) high-power detail from subcapsular region demonstrating primordial follicles and the occasional transitional follicle (arrow), but none with the well-developed cuboidal granulosa cell layer that defines primary follicles. e Preoperative ultrasound of right ovary on DOL 12: volume $0.2 \mathrm{~mL}$; note absence of antral follicles. $\mathbf{f}$ Postoperative ultrasound of right ovary on DOL 80, 7 weeks after removal of ovotestis: volume $10.9 \mathrm{~mL}$; note 2 preovulatory-sized follicles $1.6 \times 0.9$ and $1.3 \times 1.0 \mathrm{~cm}$ in diameter. g Postoperative ultrasound of right ovary on DOL 114: volume 5.6 $\mathrm{mL}$; note multiple follicles ranging from $2 \times 3 \mathrm{~mm}$ to $1.6 \times 1.6 \mathrm{~cm}$ in diameter. orchiectomy, serum AMH had fallen dramatically to a level low for either sex $(0.2 \mathrm{ng} / \mathrm{mL})$ [14]. However, testosterone only fell to $62 \mathrm{ng} / \mathrm{dL}$, remaining above the adult female range (15-50). This was coincident with hyperfunction of the remaining right ovary: baseline estradiol
Greeley/Littlejohn/Husain/Waggoner/ Gundeti/Rosenfield 
was $390 \mathrm{pg} / \mathrm{mL}$ (19-95), inhibin B $732 \mathrm{pg} / \mathrm{mL}(<16-73)$, and inhibin A $43 \mathrm{pg} / \mathrm{mL}(<20)$. At this time, GnRHag stimulation testing showed serum $\mathrm{LH}$ to be at a pubertal level and FSH suppressed, estradiol increased to $729 \mathrm{pg} /$ $\mathrm{mL}$, and testosterone increased to $82 \mathrm{ng} / \mathrm{dL}$ (Table 1). On DOL 80 , although estradiol (199 pg/mL) and testosterone (59 ng/dL) were falling, they remained above the normal mature female range. At this time, the ovary was documented to have grown to adult-size and to contain two preovulatory-sized follicles (Fig. 2e, f). The high sex steroid production gradually waned over time, in parallel with gonadotropin levels (Fig. 1) and ovarian volume and number and size of follicles (Fig. 2g). By DOL 114, serum estradiol had fallen to a pubertal level ( $44 \mathrm{pg} / \mathrm{mL})$ and testosterone was $<10 \mathrm{ng} / \mathrm{dL}$. Because testosterone elevation had been so protracted, a GnRHag test was performed to determine whether the infant had a testosterone response indicative of the presence of a testicular remnant: there was no testicular testosterone response, but $17 \mathrm{OHP}$ rose markedly (from $<25$ to $330 \mathrm{ng} / \mathrm{dL}$ ) (Table 1). Pubertal LH (9.8 IU/L) and estradiol (19 pg/mL) levels were documented through DOL 222, at which time ovarian volume was $2.97 \mathrm{~mL}$ (upper normal for age) with multiple 2-8 $\mathrm{mm}$ follicles [15]. At 1.6 years of age, ovarian volume had fallen further $(1.85 \mathrm{~mL})$, with follicles 2.8 and $5.1 \mathrm{~mm}$ in diameter; at 3 years of age, ovarian volume had fallen to $1.1 \mathrm{~mL}$ and estradiol $(<10 \mathrm{pg} / \mathrm{mL})$, testosterone $(<10 \mathrm{ng} /$ dL), LH (<0.1 IU/L), FSH (3.4 IU/L), and AMH (0.9 ng/ $\mathrm{mL}$ ) were prepubertal. Meanwhile, at 7 months of age, the family opted for feminizing genitoplasty after appropriate counseling.

\section{Discussion}

Ovotesticular DSD presentations are diverse and fall along a spectrum from a normal female [4] to a normal male phenotype [16]. Most with this disorder have genital ambiguity, which is occasionally very subtle $[17,18]$. Our patient had obvious genital ambiguity, so our findings seem pertinent to the majority of patients with ovotesticular DSD.

The clinical picture indicates that in utero, this patient's ovotestis produced insufficient testosterone to fully masculinize the genitalia, which accounts for the ambiguity of the external genitalia and persistence of incomplete Wolffian duct derivatives, and produced insufficient AMH to inhibit formation of the Müllerian system, which accounts for the presence of a normal uterus and fallopian tubes [1]. Testosterone secreted by the fetal testis during the critical period for sexual differentiation is necessary for formation of a normal penis and for Wolffian duct differentiation into the epididymis and spermatic duct. AMH secretion by the Sertoli cells of fetal testes during this critical period exerts paracrine suppression of Müllerian system differentiation, thus inhibiting ipsilateral fallopian tube and uterine differentiation [1, 19]. $\mathrm{AMH}$ is not secreted by the ovarian granulosa cells until preantral and antral follicle development begins at about 36 weeks' gestation [14].

Neonatally, after fetoplacental hormones wane within the first 5-6 days of life [20,21], serum gonadotropin levels normally rise into the pubertal range by 1 week of age [20], and serum testosterone of boys and girls is distinguishable by 9 days of age [22, 23]. Maximal pubertal hormone production (Table 1) occurs, on average, at approximately 2 months in boys [23] and 4 months in girls [24] and wanes thereafter to the prepubertal levels of childhood. Girls' gonadal function is relatively less robust than that of boys: whereas boys' serum testosterone levels rise into the midpubertal-adult range during months $2-3$ of life [23], girls' serum estradiol levels hover around the early pubertal range $[24,25]$. The meager available data suggest that during early infancy, girls' hormonal responses to GnRHag are comparable to those of pubertal girls $[26,27]$ and thus may be better than baseline levels in distinguishing prepubertal from pubertal pituitary-gonadal function, which is intermediate between prepubertal and adult function $[9,11,28,29]$. By 6 months of age, boys' testosterone typically falls to levels compatible with adrenal fetal zone origin [30], but in girls, pubertal hormone values may persist for $2-3$ years $[7,24]$. AMH production increases with the neonatal growth and development of the gonads in response to gonadotropins, with serum AMH levels of boys far exceeding those of girls until puberty, at which time serum AMH falls in boys [7, 14].

This study of a neonate with ovotesticular DSD suggests for the first time that the presence of functioning testicular tissue during the neonatal period profoundly holds ovarian follicular development and function in check and provides insight into the mechanism. The small testicular component of the ovotestis of our case was functionally predominant during the neonatal period of active gonadotropin secretion, despite internal genital duct structure indicating fetal testicular insufficiency. During the first month of postnatal life, the ovotestis displayed a robust male pattern of secretion of $A M H$ as well as testosterone, but not estradiol, in response to spontaneous and stimulated gonadotropin levels that were com- 
parable to those of adult men [31]. Histologic examination of both the excised left ovotestis and the incisional biopsy of the right ovary showed ovarian follicular development arrested at the primordial follicle stage, comparable to that in a 16-19-week fetus [7]. Thus, ovarian development did not reach the antral follicle stage at which estradiol is secreted; our histologic observations resemble that of others [32]. Following ovotestis removal, absence of testicular tissue was evidenced by a rapid decline in AMH levels. The contralateral ovary subsequently underwent massive multifollicular enlargement and became hyperfunctional, with serum levels of estradiol much higher and testosterone levels slightly higher than normal female adult values.

AMH is know from studies in animal models and human follicles cultured in vitro to inhibit progression of follicle development beyond the primordial follicle stage $[33,34]$. The data are compatible with the concept that, although testicular AMH secretion was insufficient to inhibit Müllerian system development, it generated a serum AMH level sufficiently high to account for the arrest of ovarian follicular development at the primordial follicle stage. Thus, these findings suggest that the ovarian-inhibitory effect of AMH occurs at a lower AMH level than the Müllerian-inhibitory effect of AMH. However, the doseresponse effects of $\mathrm{AMH}$ on ovarian follicle development remain to be compared at the various stages of development.

In females, $\mathrm{AMH}$ produced by the granulosa cells of small growing follicles normally appears to act as a follicular gatekeeper [35]: as follicles grow, intrafollicular AMH levels rise sufficiently to inhibit both recruitment of primordial follicles to the primary follicle stage, which involves granulosa cells organizing around the oocyte, and FSH stimulation of aromatase activity; thus, AMH limits the number of primordial follicles allowed to grow, develop, and be selected for ovulation. It has been proposed that the 3-4-fold AMH elevation characteristic of the common hyperandrogenic infertility disorder, polycystic ovary syndrome (PCOS), arises because of AMH production by the larger cohort of growing follicles produced in response to ovarian androgen excess [36]. High testosterone levels stimulate the growth of small ovarian follicles and polycystic ovary morphology in young sexually mature primates [36-38]. Our patient's serum AMH level was in the low-normal infant male range and higher than that found in PCOS. Thus, we postulate that this degree of serum AMH elevation is critical for blocking organization of primary follicles (Fig. 2a-d). This conclusion remains to be tested in sexually mature ovotesticular
DSD patients by measuring AMH. Most pregnancies reported in phenotypic females with ovotesticular DSD have occurred after removal of testicular tissue [6]; our postulate would predict that preoperatively their ovotestes generated intermediate AMH levels similar to our case. The rare ovotesticular DSD cases that have borne children after spontaneously ovulating have all had clinically profound testicular insufficiency $[4,5]$; we predict that such cases will be found to have very low AMH levels. Evidence of spontaneous ovulation has been found in the ovotestis of rare phenotypic males with ovotesticular DSD [39, 40]; while their AMH levels have not been reported, such patients have been found to have testicular germinal cell hypoplasia, which is associated with low AMH [41].

The ovarian hyperfunction after orchiectomy occurred in response to pubertal LH levels, while FSH was suppressed (Table 1). Thus, it not only seems excessive for normal female minipuberty (Table 1), it differs from the ovarian hyperfunction that is sometimes the consequence of the postmenopausal gonadotropin levels of premature infant girls $[42,43]$. Rather, it suggests that the ovarian follicles were hypersensitive to $\mathrm{LH}$, which in turn suggests that they were prematurely luteinized $[44,45]$. Premature luteinization underlies the hypersensitivity to gonadotropins in PCOS and involves inappropriately early acquisition of $\mathrm{LH}$ receptors by granulosa cells; FSH is the primary inducer of these LH receptors, and androgens enhance this and other FSH actions [46-48]. Thus, our infant's androgen exposure may well have predisposed to a PCOS type of ovarian hyperfunction.

Androgen excess may also underlie the extraordinary pace at which ovarian follicle development to the antral follicle phase took place post-orchiectomy: functioning antral follicles formed within 1 month, whereas it would have taken 3-4 months if the normal fetal pace of follicular development were simply time-shifted to begin after orchiectomy [7, 47]. The repeated GnRHag tests were too infrequent to have contributed to gonadal development, and even intermittent GnRHag administration optimized for short-term gonadotropin stimulation does not result in increased gonadal function [31]. Since androgens stimulate a 4-5-fold increase in the number of primary and small antral follicles within 10 days in the adult rhesus monkey [38], we postulate that the combination of synchronous release of follicle development from the restraining influence of $\mathrm{AMH}$ and androgenic enhancement of early-stage follicular development, which is gonadotropin independent, is responsible for our patient's rapid development of ovarian hyperfunction. 
The resemblance of this neonate's ovarian function to that of PCOS is probably more than coincidental. Congenital virilizing disorders are a risk factor for the development of PCOS, and congenital virilization induces PCOS features in diverse animal models $[49,50]$. Indeed, GnRHag test outcome on DOL 116, when ovarian function had decreased to a normal pubertal level, demonstrated an isolated rise in 17OHP secretion (from $<25$ to $330 \mathrm{ng} / \mathrm{dL}$ ) similar to that seen in PCOS [51]. We are not aware of any other report of ovarian function testing in a congenitally virilized female during the neonatal minipuberty. While these factors predict that this child is at high risk of PCOS, this remains to be documented by longterm follow-up.

This child is being raised as a female, consistent with her potential for fertility. This was a course taken with the understanding that fertility is not only potentially ham- pered by her PCOS risk, but the presence of Y chromosome-containing cells in the remaining ovary will necessitate monitoring for possible tumor development [52].

\section{Acknowledgments}

These studies could not have been carried out without the mother being as interested as we were in understanding her infant's evolving condition. S.A.W.G. was supported by a National Institutes of Health training grant T32 DK064582 and a Pediatric Endocrinology Society Research Fellowship through unrestricted funding from Novo-Nordisk.

\section{Disclosure Statement}

None of the authors has anything to disclose. The authors have no conflict of interest to declare.

\section{References}

1 Wilkins L: The Diagnosis and Treatment of Endocrine Disorders in Childhood and Adolescence. 3rd ed. Thomas C (ed.). Springfield, 1965.

2 Lee PA, Houk CP, Ahmed SF, Hughes IA: Consensus statement on management of intersex disorders. International Consensus Conference on Intersex. Pediatrics 2006; 118:e488-e500.

3 Mendez JP, Schiavon R, Diaz-Cueto L, Ruiz AI, Canto P, Soderlund D, et al: A reliable endocrine test with human menopausal gonadotropins for diagnosis of true hermaphroditism in early infancy. J Clin Endocrinol Metab 1998;83:3523-3526.

4 Tiltman AJ, Sweerts M: Multiparity in a covert true hermaphrodite. Obstet Gynecol 1982;60:752-754.

5 Schoenhaus SA, Lentz SE, Saber P, Munro MG, Kivnick S: Pregnancy in a hermaphrodite with a male-predominant mosaic karyotype. Fertil Steril 2008;90:2016.e7-e10.

-6 Schultz BA, Roberts S, Rodgers A, Ataya K: Pregnancy in true hermaphrodites and all male offspring to date. Obstet Gynecol 2009;113:534-536.

7 Kuiri-Hanninen T, Sankilampi U, Dunkel L: Activation of the hypothalamic-pituitary-gonadal axis in infancy: minipuberty. Horm Res Paediatr 2014;82:73-80.

8 Rosenfield RL, Bordini B, Yu C: Comparison of detection of normal puberty in boys by a hormonal sleep test and a gonadotropin-releasing hormone agonist test. J Clin Endocrinol Metab 2012;97:4596-4604.

>9 Rosenfield RL, Bordini B, Yu C: Comparison of detection of normal puberty in girls by a hormonal sleep test and a gonadotropin-re- leasing hormone agonist test. J Clin Endocri- 16 Alonso G, Pasqualini T, Busaniche J, Ruiz E, nol Metab 2013;98:1591-1601.

10 Bergada I, Milani C, Bedecarras P, Andreone L, Ropelato MG, Gottlieb S, et al: Time course of the serum gonadotropin surge, inhibins, and anti-Mullerian hormone in normal newborn males during the first month of life. J Clin Endocrinol Metab 2006;91:40924098.

11 Mortensen M, Ehrmann DA, Littlejohn E, Rosenfield RL: Asymptomatic volunteers with a polycystic ovary are a functionally distinct but heterogeneous population. J Clin Endocrinol Metab 2009;94:1579-1586.

12 Rosenfield RL, Mortensen M, Wroblewski K, Littlejohn E, Ehrmann DA: Determination of the source of androgen excess in functionally atypical polycystic ovary syndrome by a short dexamethasone androgen-suppression test and a low-dose ACTH test. Hum Reprod 2011;26:3138-3146.

13 Yi X, Leung EKY, Bridgman R, Koo S, Yeo K-TJ: High-sensitivity micro liquid chromatography-tandem mass spectrometry assay for serum estradiol without derivatization. J Appl Lab Med 2016;1:14-24.

14 Lindhardt Johansen M, Hagen CP, Johannsen TH, Main KM, Picard JY, Jorgensen A, et al: Anti-mullerian hormone and its clinical use in pediatrics with special emphasis on disorders of sex development. Int J Endocrinol 2013;2013:198698.

15 Badouraki M, Christoforidis A, Economou I, Dimitriadis AS, Katzos G: Evaluation of pelvic ultrasonography in the diagnosis and differentiation of various forms of sexual precocity in girls. Ultrasound Obstet Gynecol 2008;32:819-827.
Chemes H: True hermaphroditism in a phenotypic male without ambiguous genitalia: an unusual presentation at puberty. Horm Res 2007;68:261-264.

17 Kristesashvili J, Chipashvili M, Jorbenadze T, Greydanus DE: Rare cases of disorders of sex development (DSD) in adolescents with female phenotype. Int J Adolesc Med Health 2012;24:181-190.

18 Ouhilal S, Turco J, Nangia A, Stotland M, Manganiello PD: True hermaphroditism presenting as bilateral gynecomastia in an adolescent phenotypic male. Fertil Steril 2005;83: 1041.

19 Lee MM, Donahoe PK: Mullerian inhibiting substance: a gonadal hormone with multiple functions. Endocrine Reviews 1993;14:152164.

20 Winter JS, Faiman C, Hobson WC, Prasad $\mathrm{AV}$, Reyes Fl: Pituitary-gonadal relations in infancy. I. Patterns of serum gonadotropin concentrations from birth to four years of age in man and chimpanzee. J Clin Endocrinol Metab 1975;40:545-551.

21 Forest M: Function of the ovary in the neonate and infant. Eur J Obstet Gynecol Reprod Biol 1979;9:145-160.

22 Forest MG, Cathiard AM: Pattern of plasma testosterone and delta4-androstenedione in normal newborns: evidence for testicular activity at birth. J Clin Endocrinol Metab 1975;41:977-980.

23 Winter JSD, Hughes IA, Reyes Fl, Faiman C: Pituitary-gonadal relations in infancy: 2. Patterns of serum gonadal steroid concentrations in man from birth to two years of age. J Clin Endocrinol Metab 1976;42:679. 
24 Bidlingmaier F, Knorr D: Oestrogens: physiological and clinical aspects. Pediatr Adolesc Endocrinol 1978;4:43-84.

25 Chellakooty M, Schmidt IM, Haavisto AM, Boisen KA, Damgaard IN, Mau C, et al: Inhibin $\mathrm{A}$, inhibin $\mathrm{B}$, follicle-stimulating hormone, luteinizing hormone, estradiol, and sex hormone-binding globulin levels in 473 healthy infant girls. J Clin Endocrinol Metab 2003;88:3515-3520.

-26 Rosenfield RL, Burstein S, Cuttler L, Cara JF, Levitsky LL, Barnes RE, et al: Use of nafarelin for testing pituitary-ovarian function. J Reprod Med. 1989;34(suppl):1044-1050.

-27 Sir-Petermann T, Hitchsfeld C, Codner E, Maliqueo M, Iniguez G, Echiburu B, et al: Gonadal function in low birth weight infants: a pilot study. J Pediatr Endocrinol Metab 2007;20:405-414.

-28 Rosenfield RL, Wroblewski K, Padmanabhan V, Littlejohn E, Mortensen M, Ehrmann DA: Antimüllerian hormone levels are independently related to ovarian hyperandrogenism and polycystic ovaries. Fertil Steril 2012;98: 242-249.

29 Rosenfield RL: The diagnosis of polycystic ovary syndrome in adolescents. Pediatrics 2015;136:1154-1165.

- 30 Tomlinson C, Macintyre H, Dorrian CA, Ahmed SF, Wallace AM: Testosterone measurements in early infancy. Arch Dis Child Fetal Neonatal Ed 2004;89:F558-F559.

- 31 Zimmer CA, Ehrmann DA, Rosenfield RL: Potential diagnostic utility of intermittent administration of short-acting GnRH agonist administration in gonadotropin deficiency Fertil Steril 2010;94:2697-2702.

32 Kousta E, Papathanasiou A, Skordis N: Sex determination and disorders of sex development according to the revised nomenclature and classification in 46,XX individuals. Hormones 2010;9:218-231.

- 33 Durlinger AL, Kramer P, Karels B, de Jong FH, Uilenbroek JT, Grootegoed JA, et al: Control of primordial follicle recruitment by antiMullerian hormone in the mouse ovary. Endocrinology 1999;140:5789-5796.
34 Carlsson IB, Scott JE, Visser JA, Ritvos O, Themmen AP, Hovatta O: Anti-Mullerian hormone inhibits initiation of growth of human primordial ovarian follicles in vitro. Hum Reprod 2006;21:2223-2227.

35 Dewailly D, Andersen CY, Balen A, Broekmans F, Dilaver N, Fanchin R, et al: The physiology and clinical utility of anti-Mullerian hormone in women. Hum Reprod Update 2014;20:370-385 (erratum in: Hum Reprod Update 2014;20:804).

36 Jonard S, Dewailly D: The follicular excess in polycystic ovaries, due to intra-ovarian hyperandrogenism, may be the main culprit for the follicular arrest. Hum Reprod Update 2004;10:107-117.

37 Futterweit W, Deligdisch L: Histopathological effects of exogenously administered testosterone in 19 female to male transsexuals. J Clin Endocrinol Metab 1986;62:16-21.

38 Vendola KA, Zhou J, Adesanya OO, Weil SJ, Bondy CA: Androgens stimulate early stages of follicular growth in the primate ovary. J Clin Invest 1998;101:2622-2629.

39 Kanaka-Gantenbein C, Papandreou E, Stefanaki K, Fryssira H, Kolialexi A, Sophocleous $\mathrm{C}$, et al: Spontaneous ovulation in a true hermaphrodite with normal male phenotype and a rare $46, \mathrm{XX} / 47, \mathrm{XXY}$ Klinefelter's mosaic karyotype. Horm Res 2007;68:139-144.

40 Kropp BP, Keating MA, Moshang T, Duckett JW: True hermaphroditism and normal male genitalia: an unusual presentation. Urology 1995;46:736-739.

41 Goulis DG, Iliadou PK, Tsametis C, Gerou S, Tarlatzis BC, Bontis IN, et al: Serum antiMullerian hormone levels differentiate control from subfertile men but not men with different causes of subfertility. Gynecol Endocrinol 2008;24:158-160.

42 Tapanainen J, Koivisto M, Vihko R, Huhtaniemi I: Enhanced activity of the pituitarygonadal axis in premature human infants. J Clin Endocrinol Metab 1981;52:235-238.

43 Sedin G, Bergquist C, Lindgren PG: Ovarian hyperstimulation syndrome in preterm infants. Pediatr Res 1985;19:548-552.
44 Mason HD, Willis DS, Beard RW, Winston RM, Margara R, Franks S: Estradiol production by granulosa cells of normal and polycystic ovaries: relationship to menstrual cycle history and concentrations of gonadotropins and sex steroids in follicular fluid. J Clin Endocrinol Metab 1994;79:1355-1360.

45 Willis DS, Watson H, Mason HD, Galea R, Brincat M, Franks S: Premature response to luteinizing hormone of granulosa cells from anovulatory women with polycystic ovary syndrome: relevance to mechanism of anovulation. J Clin Endocrinol Metab 1998;83: 3984-3991.

46 Rani CS, Salhanick AR, Armstrong DT: Follicle-stimulating hormone induction of luteinizing hormone receptor in cultured rat granulosa cells: an examination of the need for steroids in the induction process. Endocrinology 1981;108:1379-1385.

47 Gougeon A: Regulation of ovarian follicular development in primates: facts and hypotheses. Endocrine Reviews 1996;17:121-155.

48 Weil S, Vendola K, Zhou J, Bondy CA: Androgen and follicle-stimulating hormone interactions in primate ovarian follicle development. J Clin Endocrinol Metab 1999;84:29512956.

49 Barnes RB, Rosenfield RL, Ehrmann DA, Cara JF, Cuttler L, Levitsky LL, et al: Ovarian hyperandrogenism as a result of congenital adrenal virilizing disorders: evidence for perinatal masculinization of neuroendocrine function in women. J Clin Endocrinol Metab 1994;79:1328-1333.

-50 Dumesic DA, Goodarzi MO, Chazenbalk GD, Abbott DH: Intrauterine environment and polycystic ovary syndrome. Semin Reprod Med 2014;32:159-165.

51 Rosenfield RL: The polycystic ovary morphology-polycystic ovary syndrome spectrum. J Pediatr Adolesc Gynecol 2015;28:412-419.

-52 Looijenga LH, Hersmus R, Oosterhuis JW, Cools M, Drop SL, Wolffenbuttel KP: Tumor risk in disorders of sex development (DSD). Best Pract Res Clin Endocrinol Metab 2007; 21:480-495. 